\title{
Analysis of Steam Generators Corrosion Products from Slovak NPP Bohunice
}

\author{
Jarmila Degmová, ${ }^{1}$ Július Dekan, ${ }^{2}$ Vladimír Slugeň, ${ }^{2}$ Constanze Thees, ${ }^{3}$ \\ Ivan Smieško, ${ }^{4}$ and Pavol Šeliga ${ }^{5}$ \\ ${ }^{1}$ Nuclear Research and Consultancy Group, Westerduinweg 3, 1755 ZG Petten, The Netherlands \\ ${ }^{2}$ Institute of Nuclear and Physical Engineering, Faculty of Electrical Engineering and Information Technology, \\ Slovak University of Technology in Bratislava, Ilkovicova 3, 81219 Bratislava, Slovakia \\ ${ }^{3}$ Faculty of Physics, Georg-August-Universität Göttingen, Friedrich-Hund-Platz 1, 37077 Göttingen, Germany \\ ${ }^{4}$ NPP Jaslovské Bohunice, SE, a.s., 82109 Bratislava, Slovakia \\ ${ }^{5}$ AREVA NP Controls, S.R.O., Vajnorská 13, 83104 Bratislava, Slovakia
}

Correspondence should be addressed to Jarmila Degmová, jarka_degmova@yahoo.fr

Received 9 February 2012; Accepted 28 April 2012

Academic Editor: W. Ke

Copyright ( 2012 Jarmila Degmová et al. This is an open access article distributed under the Creative Commons Attribution License, which permits unrestricted use, distribution, and reproduction in any medium, provided the original work is properly cited.

One of the main goals of the nuclear industry is to increase the nuclear safety and reliability of nuclear power plants (NPPs). As the steam generator (SG) is the most corrosion sensitive component of NPPs, it is important to analyze the corrosion process and optimize its construction materials to avoid damages like corrosion cracking. For this purpose two different kinds of SGs and its feed water distributing systems from the NPP Jaslovske Bohunice were studied by nondestructive Mössbauer spectroscopy. The samples were scraped from the surface and analyzed in transmission geometry. Magnetite and hematite were found to be the main components in the corrosion layers of both SGs. Dependant of the material the SG consisted of, and the location in the system where the samples were taken, the ratios between magnetite and hematite and the paramagnetic components were different. The obtained results can be used to improve corrosion safety of the VVER-440 secondary circuit as well as to optimize its water chemistry regime.

\section{Steam Generator}

In the Russian design of VVER-440, NPPs horizontal SGs are used. A pipeline, passing the SG wall via a nozzle, supplies the secondary side of the SG with water. The secondary side is also connected to a feed water distributing system located inside the SG. The feed water distributing system consists of a T-junction and of the left and right parts of a horizontal pipe collector with a number of short cylindrical water outlet nozzles. The horizontal pipe collector is inserted into an SG tube bundle, and it consists of $22 \mathrm{~K}$ Russian carbon steel (GOST 22K, STN 12022; see Table 1) [1-10].

As serious damages were observed in the region of the T-junction of the pipe collector and the outlet nozzles after 10 years of operation (the strong erosion caused holes as is visible in Figure 1), the former feed water distributing system was replaced by an advanced system, developed at NPP Jaslovske Bohunice [12, 13].

The original (old) steam generator with technical mark RGV-4E is one body SG $[14,15]$. The heat-exchange area is incorporated inside as surface of primary pipelines bundle with $U$-shape. The ends of these pipelines are fixed to the walls of the primary collector. Inside of SG body several separators and system of the steam water distribution are placed. The PGV-4E steam generator is foreseen for dry steam production with the pressure of about $4.61 \mathrm{MPa}$ at a temperature of about $258^{\circ} \mathrm{C}$. The basic design from 1977 was improved after 1994 by new feed water pipeline system. There was also change in the type of steel of these pipelines. Instead of conventional carbon steel, the austenite steel was used in distribution boxes as well as feed water pipelines. All components in the Bohunice innovated feed 
TABLE 1: Chemical composition of the investigated base material from the steam generators SG35 and SG46 from Jaslovske Bohunice [1$3,11]$.

\begin{tabular}{lccccccccc}
\hline SG & Type of steel & C wt $\%$ & Mn wt $\%$ & Si wt $\%$ & Cr wt $\%$ & Ni wt $\%$ & Ti wt $\%$ & P wt $\%$ & Cu wt $\%$ \\
\hline 35 & STN 17247 & Max. 0,08 & Max. 0,08 & Max. 1,0 & $17-19,0$ & $9,5-12,0$ & $*$ & 0,045 & - \\
46 & STN 12022 (GOST 22K) & $0,16-0,24$ & $0,35-0,65$ & $0,15-0,30$ & Max. 0,25 & Max. 0,25 & - & 0,04 & Max. 0,3 \\
\hline
\end{tabular}

*: Max. $5 \mathrm{x}$ C content.

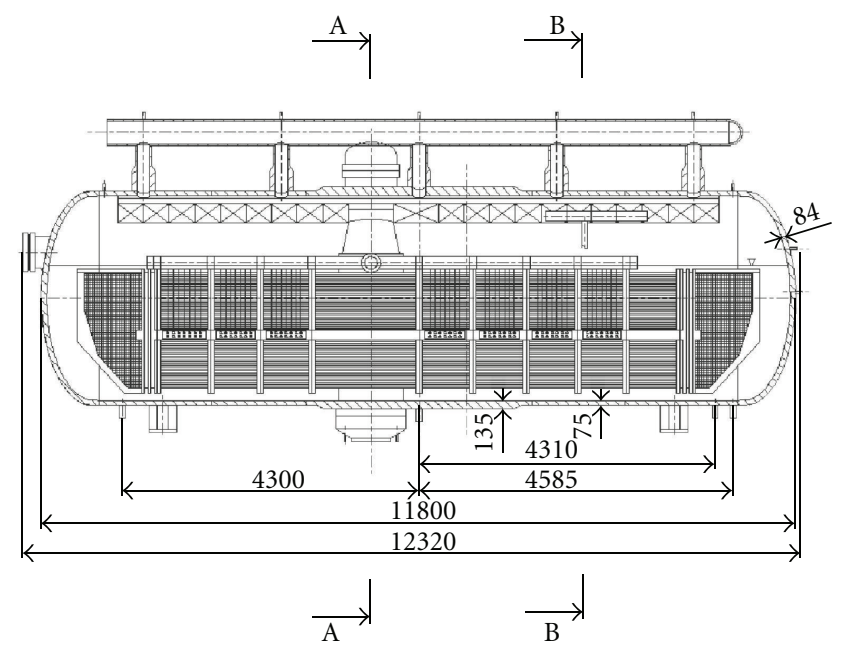

FIgURE 1: VVER-440 (Bohunice) steam generator cross-section. Bohunice innovation [14-16].

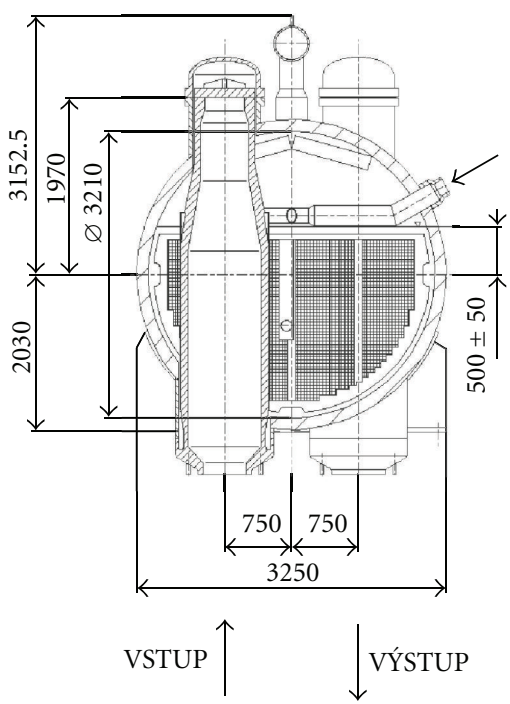

Figure 2: VVER-440 (Bohunice) steam generator cross-section AA, Bohunice innovation [14-16].

water pipeline system were made of austenitic steel according to the Czechoslovak norm ČSN, class 17. Advantages of the new construction are not only higher resistance against corrosion but also much more comfortable visual inspection. The innovations can be seen in Figures 1 and 2 .

The feed water comes via nozzle to distribution pipeline system and gets inside to left and right incoming line. From this place, water flows via pipelines $44.5 \times 4 \mathrm{~mm}$ into chambers and gets out via ejectors. This flow is mixed together with boiler water, so the final flow on the small primary pipelines is not extremely hot and does not cause a disturbing thermal load. Simultaneously, the circulation in SG tank was improved, and places with increased salt concentration are reduced.

This advanced feed water distributing system consists of a V-shaped junction connected to the left and right parts of the water distributing chambers, which are located above the tube bundle. A few feed water boxes with water ejectors are inserted into the tube bundle, and they are connected to the distributing chamber by distributing pipelines. All parts of the advanced system are manufactured from $18 \mathrm{Cr} 8 \mathrm{Ni}$ stainless steel (STN 17427; see Table 1) [1-8]

In this study some parts of the former feed water distributing system from SG46, which has a ferrite structure, were analyzed as well as parts of the innovated system from SG35 with austenitic structure. The strong erosion of the region of the T-junction of old type of SG caused holes as is visible in Figure 3.

\section{Experimental}

The Mössbauer spectroscopy (MS) was applied on the corrosion samples from two different SGs materials (see Figure 3). Five samples were scraped from different parts of each SG and, the powder was analyzed using conventional transmission Mössbauer spectrometer with ${ }^{57} \mathrm{Co}$ in $\mathrm{Rh}$ source at room temperature.

The method of Mössbauer spectroscopy is a nondestructive analytical technique with a high sensitivity to changes in the atomic configuration near the probe isotopes. The selection of the used source defines the technique's specificity for one element, in this case for ${ }^{57} \mathrm{Fe}$. MS measures hyperfine interactions so that the user is able to gain information about the magnetic and electronic state of the iron species, their chemical bonding to coordinating ligands, the local crystal symmetry at the iron sites, structural defects, latticedynamical properties, elastic stresses, and so forth [1417]. The MS spectrum shows different components if the sample atoms are located at lattice positions which are not chemically equivalent (e.g., in magnetite). It can be seen from the different subspectra, if the corresponding probe atoms are located in lattice sides which are not affected by structural defects or whether they are located at defectcorrelated positions. A superposition of all found subspectra builds the total measured spectrum. In dependence of the complexity of the sample material, the measured spectrum 


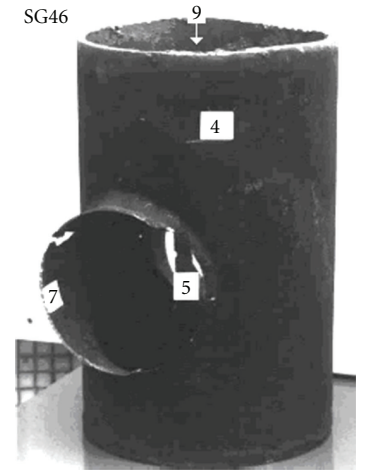

(a)

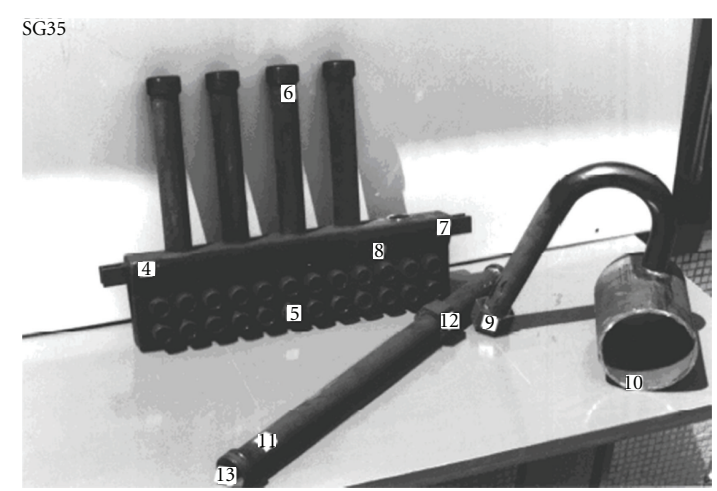

(b)

Figure 3: Parts of the SGs 46 (left, feed water dispersion tube) and 35 (right, feed water dispersion box). The places, where samples were scraped from, are marked with the corresponding number (see Table 2) $[1,3,11,19,20]$. No. 9 of SG46 can be found inside the tube.

can show even the combination of sextets, doublets, or singlets $[3,18]$.

Parts of the SGs 46 and 35 were taken out of the NPP Bohunice about 11 years ago. Scraped samples from these parts were analyzed and discussed properly in various literatures $[1-3,9,19,20]$. To compare with recently obtained data (SG42 at 2008, SG32 at 2009 and TG31, $32,41 \& 42$ at 2009) in this work, new samples were scraped of the old SG parts according to the former probe positions (Figure 3). Additionally some samples taken from the feed water distribution system of two different SGs were measured.

\section{Results and Discussion}

In measured samples iron could be found in magnetic and paramagnetic forms. The magnetic phase consists of nearly stochiometric magnetite $\left(\gamma-\mathrm{Fe}_{3} \mathrm{O}_{4}\right)$, nonstochiometric magnetite $\left(\mathrm{Fe}_{3-\mathrm{x}} \mathrm{M}_{\mathrm{x}} \mathrm{O}_{4}, \mathrm{M}_{\mathrm{x}}\right.$ : impurities and vacancies which substitute iron in octahedral B sites), hematite $\left(\alpha-\mathrm{Fe}_{2} \mathrm{O}_{3}\right)$, and iron carbides; these phases are represented in the spectra by sextets. The paramagnetic fractions are shown in Mössbauer spectra in form of a quadrupole doublet or a singlet. Its parameters are close to hydroxide (FeOOH) parameters or to parameters of small, so-called super paramagnetic particles of iron oxides (hydroxides) with the mean diameter of about $10 \mathrm{~nm}$. A list of the samples and the values obtained from fitting procedure is shown in Table 2.

3.1. Steam Generator. In three samples of SG46 base material was found, with a relative amount of 10 to $82 \%$. The corrosion samples of SG35 contained no base materials at all.

Magnetite was identified as the dominant component in nearly all studied samples. The Mössbauer spectrum of magnetite at room temperature is created by superposition of two sextets with hyperfine magnetic field $\mathrm{H}_{\mathrm{A}}=49,5 \mathrm{~T}$ $\left(\mathrm{IS}_{\mathrm{A}}=0,26 \mathrm{~mm} / \mathrm{s}\right)$ and $\mathrm{H}_{\mathrm{B}}=46,1 \mathrm{~T}\left(\mathrm{IS}_{\mathrm{B}}=0,67 \mathrm{~mm} / \mathrm{s}\right)$. As magnetite $\left(\mathrm{Fe}_{3} \mathrm{O}_{4}\right)$ crystallizes in the inverse spinel structure, where the oxygen ions form a closed packed cubic structure with Fe ions localized in two different sites, the index A corresponds to the $\mathrm{Fe}^{3+}$ ions in tetrahedral (A) sites while the index $\mathrm{B}$ corresponds to the mixed valence of $\mathrm{Fe}^{2+}$ and $\mathrm{Fe}^{3+}$ ions on the octahedral (B) sites. The cations on the B sites are indistinguishable due to fast electron transfer (hopping) $[1-3,11,19,20]$. The magnetite unit cell contains eight $\mathrm{Fe}^{3+}$ ions (A site) und eight $\mathrm{Fe}^{2+}$ and $\mathrm{Fe}^{3+}$ ions ( $\mathrm{B}$ site). For the ideal stochiometric spinel $\mathrm{Fe}_{3} \mathrm{O}_{4}$ the ratio between $\mathrm{A}$ and $\mathrm{B}$ subcomponent areas is equal to $r_{\mathrm{AB}}=0.535$. In the case that magnetite is the dominant phase in the sample, the deviation from the ideal value of $r_{\mathrm{AB}}$ should be small. Higher derivations exist due to the oxidation of magnetite, which results in the presence of vacancies or substitution in the octahedral sublattice (see Table 2) $[1-3,11,19,20]$. It is not possible to conclude anything quantitatively about the degree of oxidation; qualitatively this degree must be very low.

The other magnetic phase, which was found only in one sample of SG46, is hematite. In contrast to magnetite, it shows only one sextet in the spectra with a hyperfine magnetic field of 51.7 T. A relatively narrow line width $(\Gamma)$ of the $\alpha-\mathrm{Fe}_{2} \mathrm{O}_{3}$ indicates the presence of a well-crystallized phase with maximal a few substitutions of other elements at the Fe site. A lower hyperfine field and a larger width could be explained by a poorer crystallinity and/or a higher degree of substitution $[1-3,11,19,20]$. The line width of hematite is for the steam generator sample about $0.28 \mathrm{~mm} / \mathrm{s}$, so it is supposed to be a well-crystallized phase.

The data, which resulted of this work and which are shown in Table 2 and Figure 4, fit very well to the literature values obtained in 1998/1999 [11, 19, 20]. A comparison of the amounts of the oxides in all samples is shown in Table 3.

3.2. Feed Water Pipe and Filter Deposits. In addition to the samples from the steam generators, also six specimens from different positions of the feed water distributing system (e.g., turbogenerator (TG)) were measured with Mössbauer spectroscopy. One of these samples had been analyzed before $[11,19,20]$, and it consists of corrosion products taken from SG42 pipelines (low level). The remaining samples are taken from SG32, TG31, TG32, TG41, and TG42. They are either scraped or turbogenerator feed water integrated samples. 
TABLE 2: MS parameters of corrosion products taken from the steam generators SG46, SG35 and the feed water pipes.

\begin{tabular}{|c|c|c|c|c|c|c|c|c|}
\hline SG: pos. & $\mathrm{H}_{1 \mathrm{~A}}(\mathrm{~T})$ & $\mathrm{A}_{\text {rel }}(\%)$ & $\mathrm{H}_{1 \mathrm{~B}}(\mathrm{~T})$ & $\mathrm{A}_{\text {rel }}(\%)$ & $r_{\mathrm{AB}}$ & $\mathrm{H}_{2}(\mathrm{~T})$ & $\mathrm{A}_{\text {rel }}(\%)$ & Additional components \\
\hline $46: 50$ & 49,6 & 51,9 & 46,1 & 34,2 & 1,5 & & & $\mathrm{~B}, \mathrm{D}$ \\
\hline $46: 7 \mathrm{o}$ & 49,7 & 11,5 & 46,3 & 7,0 & 1,6 & & & B \\
\hline $46: 7 \mathrm{i}$ & 49,5 & 21,2 & 46,0 & 15,8 & 1,3 & & & B \\
\hline 46: 40 & 49,6 & 40,1 & 46,2 & 59,9 & 0,7 & & & \\
\hline $46: 9 \mathrm{i}$ & 49,7 & 35,3 & 46,3 & 53,2 & 0,7 & 51,8 & 10,0 & \\
\hline 35: 6 & 49,7 & 38,4 & 46,3 & 61,6 & 0,6 & & & \\
\hline 35: 5 & 49,7 & 33,2 & 46,3 & 66,8 & 0,5 & & & \\
\hline 35: 4 & 49,5 & 36,3 & 46,1 & 56,7 & 0,6 & & & S \\
\hline 35: 9 & 49,5 & 37,9 & 46,2 & 62,1 & 0,6 & & & \\
\hline 35: 10 & 49,6 & 36,1 & 46,2 & 52,2 & 0,7 & & & $\mathrm{D}, \mathrm{S}$ \\
\hline $42 \mathrm{pl}$ & 49,4 & 41,3 & 46,1 & 58,7 & 0,7 & & & \\
\hline $32 \mathrm{pl}$ & 49,3 & 34,8 & 46,1 & 57,0 & 0,6 & 51,6 & 8,1 & \\
\hline (1) 09 (TG31) & 49,3 & 23,0 & 46,0 & 34,2 & 0,7 & 51,7 & 34,6 & $\mathrm{D}$ \\
\hline (2) 09 (TG32) & 49,4 & 24,8 & 46,1 & 29,9 & 0,8 & 51,9 & 41,4 & $\mathrm{D}$ \\
\hline (3) 09 (TG41) & 49,4 & 24,9 & 45,9 & 24,2 & 1,0 & 51,8 & 40,4 & $\mathrm{D}$ \\
\hline (4) 09 (TG42) & 49,3 & 27,5 & 45,9 & 30,0 & 0,9 & 51,9 & 24,3 & $\mathrm{D}$ \\
\hline
\end{tabular}

Outside (o), inside (i) (position, where the samples were taken), pipeline (pl), doublet presence (D), singlet (S), magnetite's hyperfine magnetic field in Tesla $\left(\mathrm{H}_{1 \mathrm{~A}}, \mathrm{H}_{1 \mathrm{~B}}\right)$, ratio between $\mathrm{A}$ and $\mathrm{B}$ subcomponent areas in magnetite $\left(r_{\mathrm{AB}}\right)$, hematite's hyperfine magnetic field in Tesla $\left(\mathrm{H}_{2}\right)$, base material presence $(\mathrm{B})$, area of the component in the spectra in $\%\left(\mathrm{~A}_{\text {rel }}\right)$.

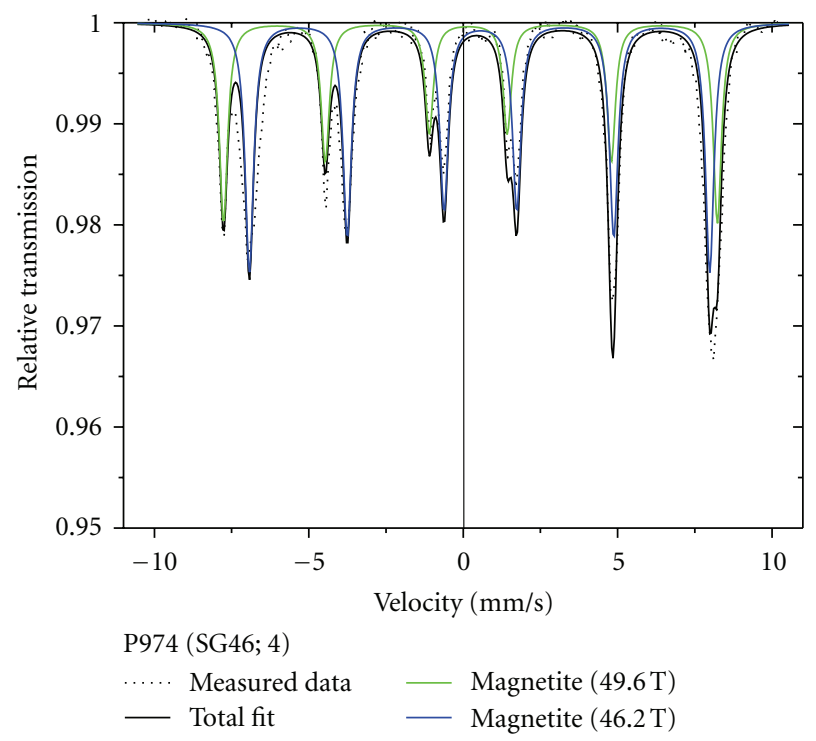

(a)

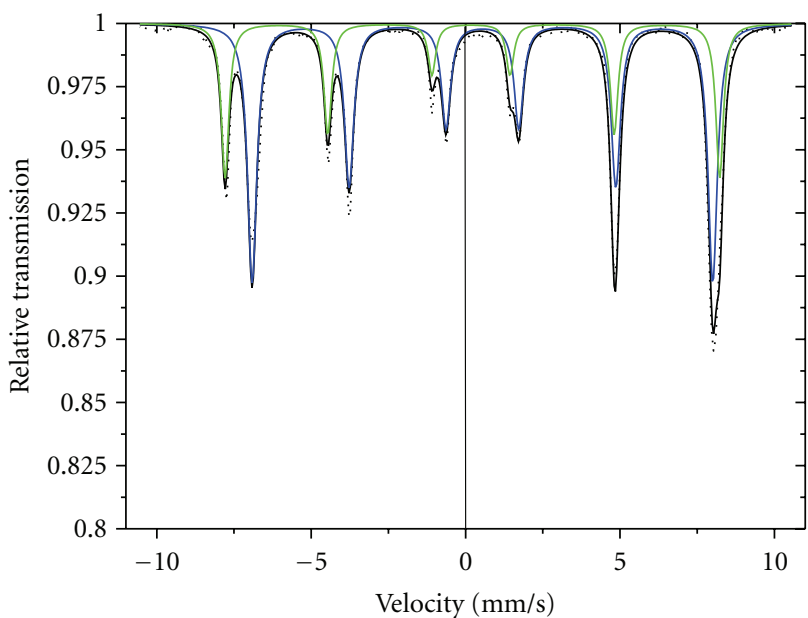

R007 (SG35; 5)

$\begin{array}{ll}\cdots & \text { Measured data } \\ \text { Total fit } & \text { Magnetite }(49.7 \mathrm{~T}) \\ & \text { Magnetite }(46.3 \mathrm{~T})\end{array}$

(b)

FIGURE 4: Mössbauer spectra of SG46 and SG35 samples. Both samples contain only magnetite.

The spectra show that most of the samples consist of magnetite as well as of hematite, whose amount decreases towards the steam generator. The existence of the different iron oxides is due to the boiling water $\left(260^{\circ} \mathrm{C}\right)$ with higher salt concentration outside the system, while the water inside has temperatures between 158 and $225^{\circ} \mathrm{C}$.

In Figure 5 the spectrum of sample S1-09 can be seen. It consists of three magnetically split components, where two of them were assigned to magnetite, and the remaining component was identified as hematite. The doublet corresponds to the paramagnetic part of the spectrum and represents hydroxide. The spectra of the other samples look very similar to the one shown in Figure 5.

The most corroded parts of the former feed water pipes are near the T-junctions. Due to dynamic effects of the water flow with high pressures and high forces on the inner pipe wall in the region of T-junction, the content of corrosion products was reduced and moved into the secondary unit. Particles of the feed water tube base materials could be identified in sediments of SG46 [11, 19, 20].

The hematite line width of the feed water pipe specimen is about $0.30-0.33 \mathrm{~mm} / \mathrm{s}$, so that these samples show a poorer 
TABle 3: Comparison of the results from this work with literature data. Magnetite (M), hematite (H), doublet (D), singlet (S). The base material is not included.

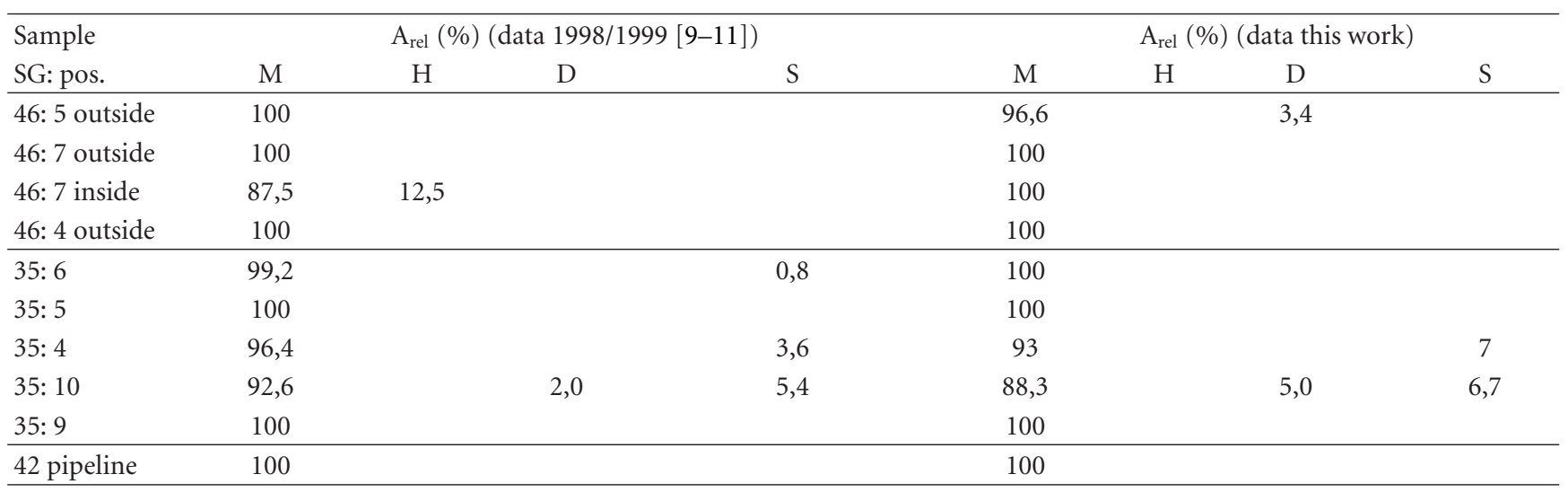

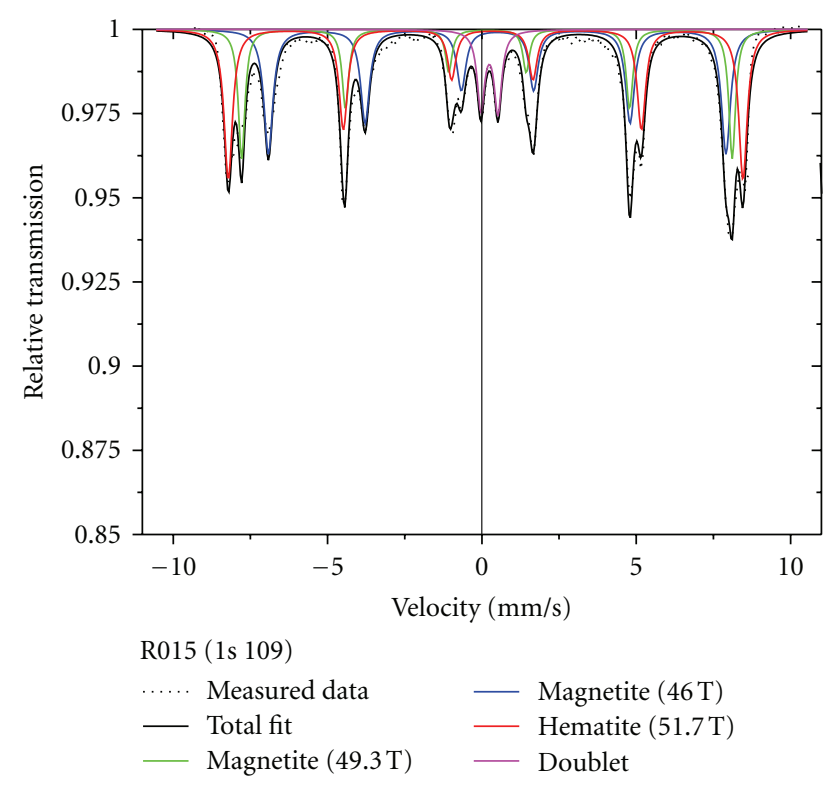

FIGURE 5: Mössbauer spectrum of one of samples taken from the feed water distribution system. The spectrum contains magnetic subspectra (magnetite and hematite) and one paramagnetic subspectrum in form of a quadrupole doublet.

crystallinity in comparison to the steam generator results. The samples from feed water system of turbogenerators showed quite high concentration of hematite with comparison with the rest of the samples set. This could be due to higher oxygen concentration in the pipes during reactor power operation and also during reactor shutdown, when the samples were collected.

The results of this work show qualitatively the same oxides content for the samples taken from SG42, SG46, and SG35 as it was measured before by Slugen et al. [11, 19, 20], with very comparable representation. This indicates that the air corrosion did not take place during storage of SG pieces in laboratory conditions (see Table 3).

\section{Conclusions}

Mössbauer spectroscopy analysis performed at specimens from NPP Bohunice steam generators and other secondary circuits components confirmed that corrosion in combination with erosion can cause substantial damages in the feed water distributing systems. The resulting Mössbauer spectra show that the main components of secondary circuit's corrosion products are magnetite and hematite with a higher amount of magnetite.

Due to these results and the immense importance of nuclear safety, a replacement of the previous version of steam generator feed water system is important. The new steel STN 17247 shows a better corrosion behavior without containing hematite.

The samples taken from the feed water pipe system show a fraction of hematite $(24 \%-42 \%)$ and also paramagnetic quadrupole doublets (3\%-19\%). So the material/design of the feed water distributing system needs further improvements.

\section{Acknowledgments}

Authors acknowledge support from Association Euroatom. $\mathrm{CU}$ and Grants from Slovak ministry of education: VEGA 1/0119/12 and VEGA 1/0366/12.

\section{References}

[1] J. Lipka, V. Slugen, I. Toth, J. Hascik, and M. Lehota, "Phase analysis of corrosion products from nuclear power plants," Hyperfine Interactions, vol. 139-140, no. 1-4, pp. 501-511, 2002.

[2] V. Slugen, J. Lipka, I. Toth, J. Hascik, M. Lehota, and I. Smiesko, "Application of Mössbauer spectroscopy in phase analysis of corrosion products from nuclear power plants," Czechoslovak Journal of Physics, vol. 51, no. 9, pp. 909-916, 2001.

[3] V. Slugeň, J. Lipka, I. Tóth, J. Hašč́k, Hinca, and M. Lehota, "Corrosion of steam generator pipelines analysed using Mössbauer spectroscopy," Nuclear Engineering and Design, vol. 235, no. 17-19, pp. 1969-1976, 2005. 
[4] D. Lucan, "Behaviour of the steam generator tubing in water with different $\mathrm{pH}$ values," Nuclear Engineering and Design, vol. 241, no. 4, pp. 1172-1176, 2011.

[5] D. R. Diercks, W. J. Shack, and J. Muscara, "Overview of steam generator tube degradation and integrity issues," Nuclear Engineering and Design, vol. 194, no. 1, pp. 19-30, 1999.

[6] T. Dvoršek, L. Cizelj, and B. Mavko, "Safety and availability of steam generator tubes affected by secondary side corrosion," Nuclear Engineering and Design, vol. 185, no. 1, pp. 11-21, 1998.

[7] P. Tipping, "Lifetime and ageing management of nuclear power plants: a brief overview of some light water reactor component ageing degradation problems and ways of mitigation," International Journal of Pressure Vessels and Piping, vol. 66, no. 1-3, pp. 17-25, 1996.

[8] K. Varga, Z. Németh, A. Szabó et al., "Comprehensive investigation of the corrosion state of the heat exchanger tubes of steam generators. Part I. General corrosion state and morphology," Journal of Nuclear Materials, vol. 348, no. 1-2, pp. 181-190, 2006.

[9] B. Baja, K. Varga, N. A. Szabó et al., "Long-term trends in the corrosion state and surface properties of the stainless steel tubes of steam generators decontaminated chemically in VVER-type nuclear reactors," Corrosion Science, vol. 51, no. 12, pp. 2831-2839, 2009.

[10] Z. Homonnay, E. Kuzmann, K. Varga et al., "Comprehensive investigation of the corrosion state of the heat exchanger tubes of steam generators. Part II. Chemical composition and structure of tube surfaces," Journal of Nuclear Materials, vol. 348, no. 1-2, pp. 191-204, 2006.

[11] V. Slugen, J. Lipka, J. Dekan, I. Tóth, and I. Smieško, "Long-term corrosion study at nuclear power plant Bohunice (Slovakia)," Journal of Physics, vol. 217, no. 1, Article ID 012069, 2010.

[12] V. Slugen, J. Lipka, J. Dekan, J. Degmova, and I. Toth, "Phase composition study of corrosion products at NPP," in Nuclear Power Plants, S. H. Chang, Ed., pp. 317-340, InTech, Rijeka, Croatia, 2012.

[13] V. Slugen, Safety of VVER-440 Reactors: Barriers Against Fission Products Release, Springer-Verlag, London, UK, 2011.

[14] Technical descripcion of SG PGV-4E, T-1e, (B-9e/241/), 1978.

[15] "Steamgenerator," Tech. Rep. DTC 1.01.2-1.unit V1, 1994, Documentation to real status to 30.4.1994.

[16] Safety report V-1, chapter IV.3 Primary circuit, Normative documentation A-01/1,2, 1978.

[17] N. N. Greenwood and T. C. Gibb, Mössbauer Spectroscopy, Chapman and Hall, London, UK, 1971.

[18] J. Lipka, "Mössbauer spectroscopy used for testing of reactor steels," Czechoslovak Journal of Physics, vol. 51, no. 5, pp. 503$511,2001$.

[19] V. Slugen, J. Lipka, J. Dekan et al., "Observation of long-term corrosion at nuclear power plant Bohunice (Slovakia)," in Proceedings of the International Conference "Nuclear Energy for New Europe”, (NENE '10), pp. 603.1-603.5, Portorož, Slovenia, September 2010.

[20] V. Slugen, J. Lipka, J. Dekan, I. Toth, and I. Smiesko, "Corrosion at nuclear power plant from MS point of view," in Proceedings of the International Conference on Mossbauer Spectroscopy in Materials Science, AIP Conference, pp. 120-126, February 2010. 

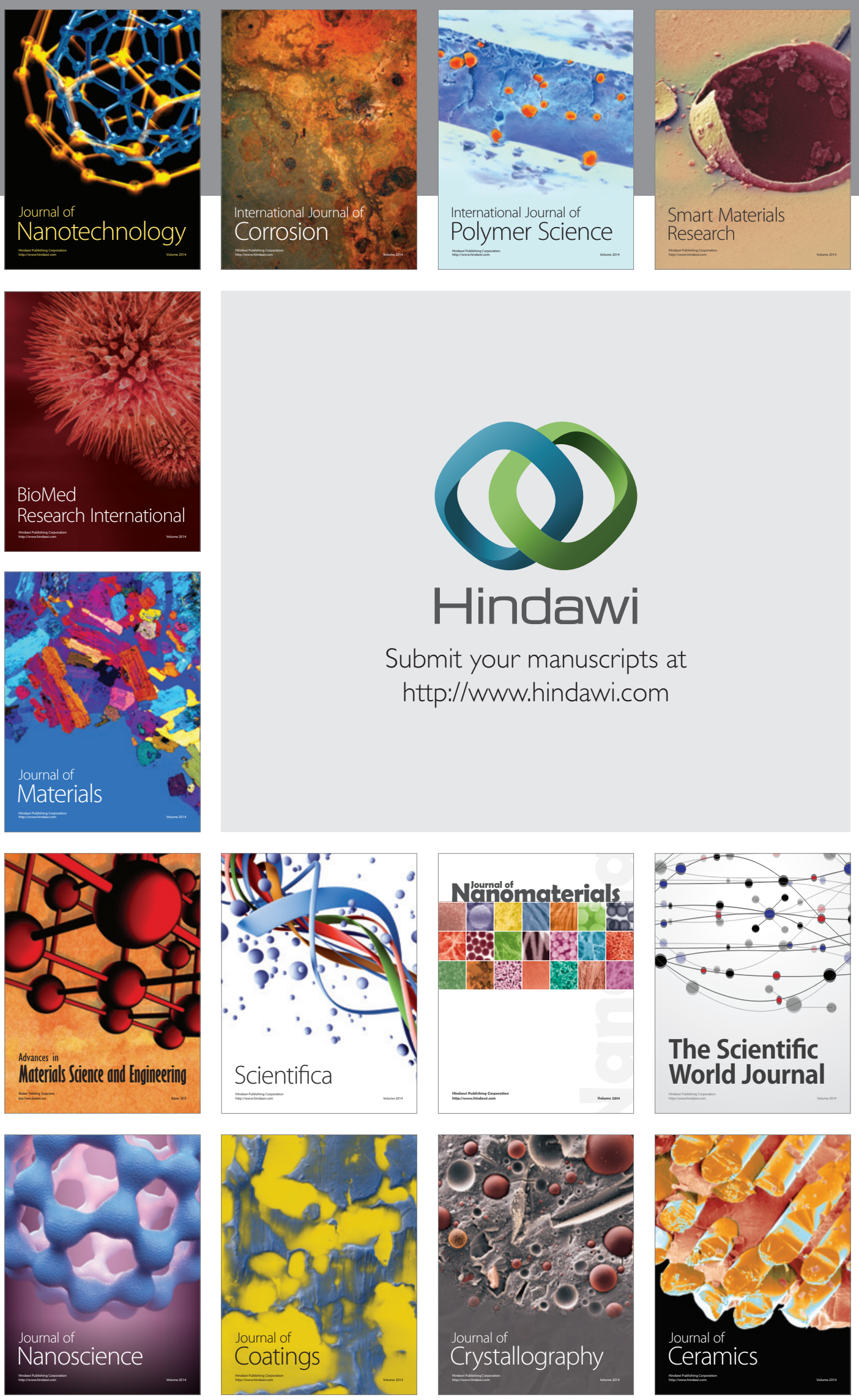

The Scientific World Journal

Submit your manuscripts at

http://www.hindawi.com

\section{World Journal}

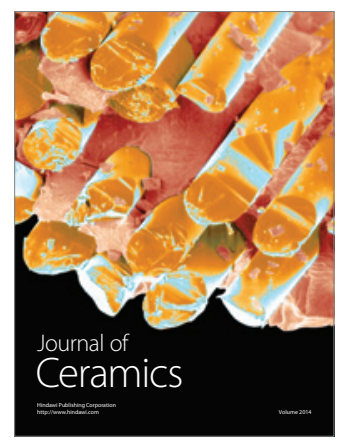

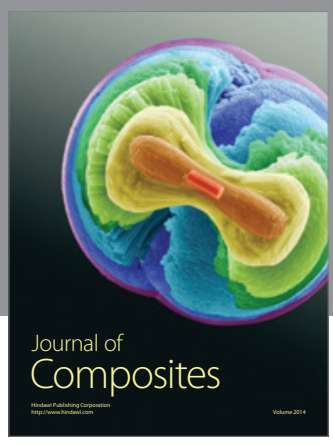
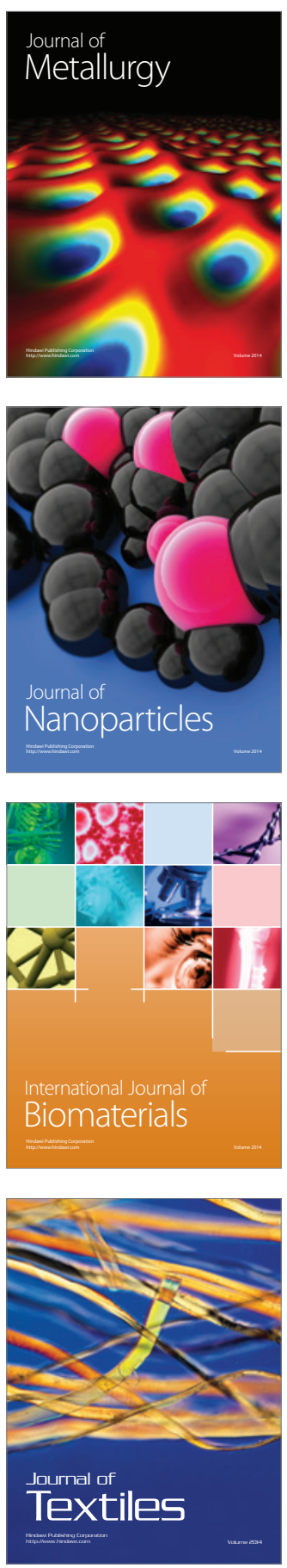